\title{
Oasis cold island effect and its influence on air temperature: a case study of Tarim Basin, Northwest China
}

\author{
HAO Xingming ${ }^{*}$, LI Weihong \\ State Key Laboratory of Desert and Oasis Ecology, Xinjiang Institute of Ecology and Geography, Chinese Academy of Sciences, \\ Urumqi 830011, China
}

\begin{abstract}
Oasis effect can improve the regional climate and habitability of an arid region. In this study, we explored the cold island effects of oases distributed along the edge of Tarim Basin by analyzing the oasis cold island effect (OCIE) intensity, spatial-temporal variation of OCIE, factors influencing the OCIE and impacts of OCIE on air temperature using geographical statistics and GIS methods based on the MODIS land surface temperature, land use/cover change (LUCC) and observed air temperature data. Results showed that all the oases in the Tarim Basin exhibited cold island effects, with the $\mathrm{OCIE}$ intensity highest in summer $\left(-9.08^{\circ} \mathrm{C}\right)$, followed by autumn $\left(-4.24^{\circ} \mathrm{C}\right)$ and spring $\left(-3.85^{\circ} \mathrm{C}\right)$. The total area of oasis cold island $(\mathrm{OCI})$ and the comprehensive OCIE index showed the same seasonal change trend as the OCIE intensity. However, the changing trends in areas of $\mathrm{OCl}$ with strong, medium and weak OCIEs were inconsistent across different seasons. Farmland and water areas were found to be the key contributors that affected the OCIE, and the area and aggregation metrics of these two land use/cover types directly contributed to the OCIE. By contrast, natural vegetation, such as forest and grassland, almost had no contribution to the OCIE. Simulation of observed air temperature data showed that if farmland is replaced by forest or grassland in the oasis, the mean, maximum and minimum air temperatures will increase significantly. This heating effect will be higher in summer (reaching $1.14^{\circ} \mathrm{C}$ to $2.08^{\circ} \mathrm{C}$ ) and lower in spring and autumn. Moreover, the heating effect of farmland being replaced by forest will be higher than that of farmland being replaced by grassland. These results can provide a basis for understanding the cold island effect of oases in arid regions.
\end{abstract}

Keywords: oasis cold island effect; comprehensive oasis cold island effect index; landscape index; oasis evolution; arid environment

Citation: HAO Xingming, LI Weihong. 2016. Oasis cold island effect and its influence on air temperature: a case study of Tarim Basin, Northwest China. Journal of Arid Land, 8(2): 172-183. doi: 10.1007/s40333-015-0060-x

Oasis is a medium- or small-sized non-zonal landscape in arid regions and is supported by natural rivers in deserts. It is characterized by relatively high primary productivity and has mesophytic or xero-mesophytic plants as the dominant species. Oases play an important role in arid regions of Northwest China. Although their total area is less than $10 \%$ of the total land area of Northwest China, they support $90 \%$ of the population and contribute to $95 \%$ of the total economic output ( $\mathrm{Li}$ et al., 2011; Chen and Chen, 2013). However, all of these benefits are derived at the cost of high water consumption (Liu et al., 2010). In fact, an oasis can be viewed as a water consumption center in an arid region. For this reason, oasis effect or oasis cold island effect (OCIE) has always

${ }^{*}$ Corresponding author: HAO Xingming (E-mail: haoxm@ms.xjb.ac.cn)
Received 2015-06-06; revised 2015-09-16; accepted 2015-10-09
(C) Xinjiang Institute of Ecology and Geography, Chinese Academy of Sciences, Science Press and Springer-Verlag Berlin Heidelberg 2016 
been an active area of researches in recent years (Taha et al., 1991; Chu et al., 2005; Potchter et al., 2008).

The OCIE is particularly prominent in arid regions because of regional high temperature and dry climate. Su and $\mathrm{Hu}$ (1987) initially proposed the OCIE through a numerical model of the planetary atmospheric boundary layer. Subsequently, several observation and simulation studies have verified that the oasis possesses the cold island effect (Taha et al., 1991; Wen et al., 2005; Potchter et al., 2008; Han et al., 2010; Li et al., 2011). At present, the approaches for studying the OCIE mainly involve field observation and numerical simulation. Field observations have revealed the impacts of OCIE on air temperature and wind speed (Taha et al., 1991). In addition, some observations have also showed that the OCIE is closely related to vegetation types and can change the heat flux process on the oasis surface (Potchter et al., 2008; Han et al., 2010). However, field observations can only reveal the cold island effect of a single oasis and the observation period is usually short (only a few days) because of the limited number of observation sites. By contrast, the numerical simulation studies are more focused on the driving mechanism of OCIE (Chu et al., 2005; Liu et al., 2007; Li et al., 2011). These studies indicated that secondary and mesoscale circulations are the important driving forces of OCIE. However, numerical simulation also has the obvious disadvantage, and it usually cannot provide adequate detailed information on the OCIE. Although some important progresses have been made in the studies of OCIE, some problems still need to be further studied: (1) temporal and spatial variations of OCIE at large scales (regional scales, including many oases); (2) the complex relationship between land use/cover types and the OCIE; and (3) impacts of oasis-making process on the observed air temperature in oases.

In order to answer the above questions, we studied the cold island effects of oases distributed at the edge of Tarim Basin in Northwest China. MODIS land surface temperature (LST), land use/cover types and observed meteorological data were also analyzed. This study aimed to: (1) reveal the change characteristics of OCIE at different time scales and the spatial variation of OCIE; (2) analyze the mechanism of OCIE by exploring the influence of land use/cover types on the OCIE; and (3) estimate the impact of oasis-making process (the process of artificial vegetation replacing natural vegetation) on air temperature in an oasis.

\section{Materials and methods}

\subsection{Study area}

The Tarim Basin is located in the Northwest China, bordered by the Tianshan Mountains in the north, and Kunlun and Altun mountains in the south. It is about 1,500 km long from east to west and $600 \mathrm{~km}$ wide from north to south. The basin has an area of $53 \times 10^{4} \mathrm{~km}^{2}$ and its altitude ranges from 800 to $1,300 \mathrm{~m}$. The basin's center is the famous Taklimakan Desert, and therefore, oases can only be distributed at the edge of the basin. The large oases in the Tarim Basin include the Bosten Lake, Konqi River, Ogan-Kuqa river, Aksu River, Kaxgar River, Yarkant River, Hotan River and Keriya River oases (Fig. 1). These oases are all formed along the river/lake systems, and larger river/lake runoffs usually lead to the formation of larger oases. In the Tarim Basin, Yarkant River oasis is the largest oasis with an area $1.73 \times 10^{4} \mathrm{~km}^{2}$, followed by Aksu River $\left(1.63 \times 10^{4} \mathrm{~km}^{2}\right)$, Kaxgar River $\left(1.06 \times 10^{4} \mathrm{~km}^{2}\right)$, Ogan-Kuqa river $\left(0.81 \times 10^{4} \mathrm{~km}^{2}\right)$, Hotan River $\left(0.72 \times 10^{4} \mathrm{~km}^{2}\right)$, Konqi River $\left(0.68 \times 10^{4} \mathrm{~km}^{2}\right)$ and Bosten Lake $\left(0.78 \times 10^{4} \mathrm{~km}^{2}\right)$ oases. Keriya River oasis is the smallest oasis with an area of only $0.49 \times 10^{4} \mathrm{~km}^{2}$. This region is characterized by a typical continental arid climate, with scarce rainfall, sudden changes in temperature and extremely dry climate. In the plain areas (mainly referring to oases) of Tarim Basin, the annual mean temperature is about $11.7^{\circ} \mathrm{C}$, the mean annual precipitation is $76.2 \mathrm{~mm}$ and the annual mean relative humidity is about $50 \%$; while in the mountain areas, the annual mean temperature is $2.0^{\circ} \mathrm{C}$, the mean annual precipitation is $218.7 \mathrm{~mm}$ and the annual mean relative humidity is about $55 \%$. Cotton, wheat, rice and corn are the main crops in these oases.

\subsection{Data and methods}

1.2.1 Data collection

The MODIS LST data (MOD11A2 level data, February 2000-December 2013) were downloaded 


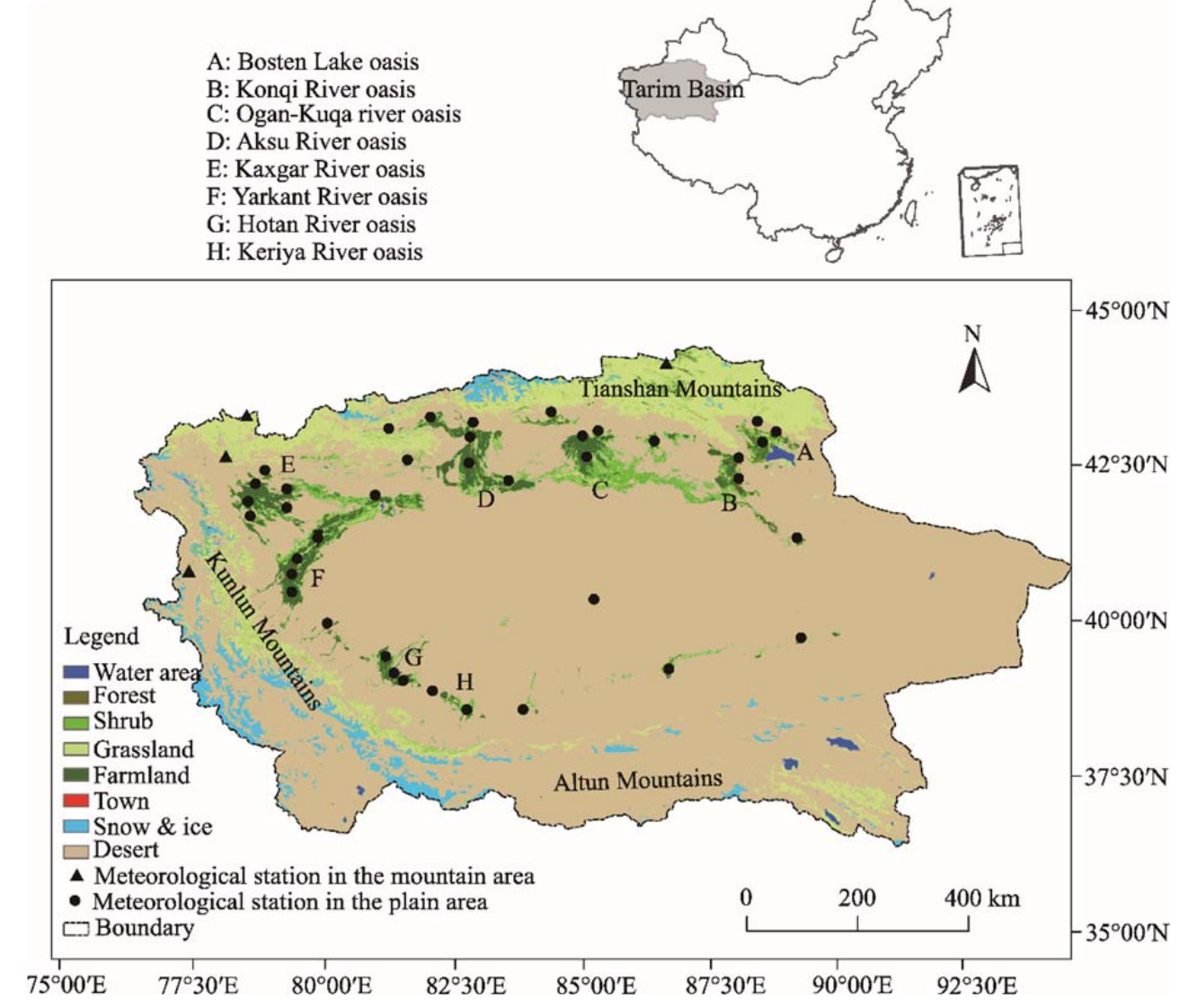

Fig. 1 Map of the study area

from the website of the National Aeronautics and Space Administration (http://modis.gsfc.nasa.gov/). The temporal and spatial resolutions of the data are $8 \mathrm{~d}$ and $1 \mathrm{~km} \times 1$ $\mathrm{km}$, respectively. We processed the MODIS data by using the MODIS Reprojection Tool to generate a Tagged Image File Format in the WGS84 coordinate system. We analyzed this product using the split-window method (Wan and Li, 1997) to estimate surface emissivity and temperature. Temperature values were at Kelvin scale, and we only used pixels with LST error $<1 \mathrm{~K}$, as indicated by the quality assessment information included in the MOD11A2 data series. In this study, we calculated the mean day and night LST in spring, summer and autumn based on the LST data series from 2000 to 2013 and converted all temperature values from Kelvin to Celsius scales. All data were further analyzed using ArcGIS 10.0 software (ESRI, Redlands, CA, USA).

The land use/cover change (LUCC) data (MOD12Q1 during 2001-2013, land use/cover at 500-m resolution) were downloaded from http://modis.gsfc.nasa.gov/. We corrected the MODIS LUCC data based on the 1:100,000 land use map of 2000, and the correction was mainly for sparse vegetation of the MODIS IGBP classification system. The LUCC data were resampled (using nearest neighbor) to $1 \mathrm{~km}$ resolution, which matched the spatial resolution of the LST data.

The meteorological data from 2000 to 2013, including daily mean, maximum and minimum air temperatures, were obtained from 43 meteorological stations (including 4 stations in the mountain areas) in the study area (Fig. 1). Using this data set, we calculated the mean, maximum and minimum air temperatures in spring, summer and autumn during 2000-2013.

\subsubsection{Analysis methods}

We considered the city/town of each oasis as the center of this region, and made two profile lines from north to south and west to east. The profile line covered the desert and oasis landscapes. It started from the desert, then included the entire oasis, and ended in the desert again. We extracted 
the LST data in spring, summer and autumn for each oasis along these profile lines using the ArcGIS 10.0 software.

Based on the land use/cover map of each oasis, we initially determined the boundary of the core zone (farmland) of each oasis, considered this boundary as the benchmark, and then outward buffered $20 \mathrm{~km}$ using the ArcGIS 10.0 software. Thus, the final boundary of the buffer zone of each oasis is the boundary of each oasis cold island (OCI). We excluded the mountainous areas from the buffer zone analysis.

In this study, we used two methods to define the OCIE. The first method is the OCIE intensity, which is the difference of mean LST between the oasis and desert areas (Schwarz et al., 2011). The OCIE intensity always had a negative value because LST in the oasis was generally lower than that in the desert. Moreover, a higher absolute value of OCIE intensity indicates that LST in the oasis is lower, and the OCIE is more intense. The second method is the classification of the oasis LST based on the mean LST of the desert area (Yang et al., 2006). This method reflects the intensity of OCIE and the difference in areas of OCI with different OCIE intensities. The classification standards and methods are shown in Table 1.

Table 1 Classification standards and methods of OCIE (oasis cold island effect)

\begin{tabular}{lll}
\hline Index & Classification standard & Classification method \\
\hline \multirow{3}{*}{ OCIE } & Non-cold island effect & $\mathrm{LST}_{\mathrm{o}} \geq \mathrm{LST}_{\mathrm{d}}$ \\
& Weak OCIE & $\mathrm{LST}_{\mathrm{d}}-2.5^{\circ} \mathrm{C} \leq \mathrm{LST}_{\mathrm{o}}<\mathrm{LST}_{\mathrm{d}}$ \\
& Medium OCIE & $\mathrm{LST}_{\mathrm{d}}-5^{\circ} \mathrm{C} \leq \mathrm{LST}_{\mathrm{o}}<\mathrm{LST}_{\mathrm{d}}-2.5^{\circ} \mathrm{C}$ \\
& Strong OCIE & $\mathrm{LST}_{\mathrm{o}}<\mathrm{LST}_{\mathrm{d}}-5^{\circ} \mathrm{C}$ \\
\hline
\end{tabular}

Note: $\mathrm{LST}_{\mathrm{o}}$ and $\mathrm{LST}_{\mathrm{d}}$ are the mean LST in the oasis and desert, respectively.

Considering that the OCIE is the combined result of OCIE intensity and area, we constructed an evaluation index (comprehensive OCIE index) that can reflect their roles.

Comprehensive OCIE index $=\sum W_{i} A_{i}$.

Where, $W_{i}$ is the weight of the areas of OCI with different OCIE intensities. In this study, we assigned the weights of 3,2 and 1 to the areas of OCI with strong, medium and weak OCIEs, respectively. $A_{i}$ is the ratio of the areas of OCI with strong, medium and weak OCIEs to the total area of each oasis.

Farmland, water area, forest and grassland are the main land use/cover types in the oases of Tarim Basin. We calculated the metrics of area and edge, shape, aggregation and core area of these land use/cover types of each oasis during 2001-2013 based on the LUCC map (Table 2). We also calculated the landscape diversity index of each oasis, including Shannon's diversity index (SHDI), Shannon's evenness index (SHEI) and modified Simpson's evenness index (MSIEI). All these calculations were performed using the Fragstats software 4.2. In this study, we calculated the mean value of the above metrics to determine the land use/cover state of the study area from 2001 to 2013.

\section{Results}

\subsection{Change characteristics of LST and OCI}

The cold island effect was commonly observed in the oasis area in summer and was manifested obviously under the low LSTs (Fig. 2). The daily LST showed a changing pattern of high-lowhigh corresponding with the transitions of land use/cover types from desert to oasis to desert in the NS and WE directions. The average difference between the minimum LST of oasis and the mean LST of desert was $12.95^{\circ} \mathrm{C}$ in the entire basin, and the maximum and minimum differences occurred in the Bosten Lake $\left(15.24^{\circ} \mathrm{C}\right)$ and Kaxgar River $\left(9.42^{\circ} \mathrm{C}\right)$ oases, respectively. In the entire basin, the spatial boundary of the low LST region was mostly consistent with the scope of the oasis. The maximum and minimum lengths of the low LST region were 149 and $42 \mathrm{~km}$ in the Yarkant River and Keriya River oases, respectively, along the NS direction; meanwhile, the 
maximum and minimum lengths were 103 and $33 \mathrm{~km}$ in the Kaxgar River and Keriya River oases, respectively, along the WE direction. Compared to the change trend in LST during daytime, the difference of LST between the oasis and desert was smaller at night, indicating that OCIE was weak or absent during nighttime.

Table 2 Metrics and indices of land use/cover types and landscape used in this study

\begin{tabular}{|c|c|c|c|c|}
\hline \multirow{2}{*}{$\begin{array}{l}\text { Metric } \\
\text { Area and edge }\end{array}$} & \multicolumn{2}{|c|}{ Index of land use/cover type } & \multicolumn{2}{|c|}{ Index of landscape } \\
\hline & $\mathrm{CA}$ & Total class area & 1 & 1 \\
\hline & PLAND & Percentage of landscape & 1 & 1 \\
\hline & LPI & Largest patch index & 1 & 1 \\
\hline & AREA_MN & Mean patch area & 1 & 1 \\
\hline \multirow[t]{3}{*}{ Shape } & PARA_MN & Mean perimeter area ratio & 1 & 1 \\
\hline & FRAC_MN & Mean patch fractal dimension & 1 & 1 \\
\hline & SHAPE_MN & Mean shape index & 1 & 1 \\
\hline \multirow[t]{4}{*}{ Aggregation } & AI & Aggregation index & 1 & 1 \\
\hline & COHESION & Patch cohesion index & 1 & 1 \\
\hline & SPLIT & Splitting index & 1 & 1 \\
\hline & ENN_MN & $\begin{array}{l}\text { Mean Euclidean } \\
\text { nearest-neighbor distance }\end{array}$ & 1 & 1 \\
\hline \multirow[t]{3}{*}{ Core area } & TCA & Total core area & 1 & 1 \\
\hline & CPLAND & Core area percentage of landscape & 1 & 1 \\
\hline & CORE_MN & Mean core area & 1 & 1 \\
\hline \multirow[t]{3}{*}{ Diversity } & 1 & 1 & SHDI & Shannon's diversity index \\
\hline & 1 & 1 & SHEI & Shannon's evenness index \\
\hline & 1 & 1 & MSIEI & Modified Simpson's evenness index \\
\hline
\end{tabular}

Note: $\backslash$ means that when considering the index of land use/cover type, the index of landscape is not considered, and vice versa.

The OCIE intensity during daytime was highest in summer with an average value of $-9.08^{\circ} \mathrm{C}$ across all oases, followed by autumn, with an average value of $-4.24^{\circ} \mathrm{C}$ (Fig. 3). The OCIE intensity during daytime was lowest in spring with an average value of $-3.85^{\circ} \mathrm{C}$. Variation of OCIE intensity across all oases ranged from $-12.82^{\circ} \mathrm{C}$ (Hotan River oasis) to $-6.69^{\circ} \mathrm{C}$ (Kaxgar River oasis) in summer, $-7.01^{\circ} \mathrm{C}$ (Hotan River oasis) to $-2.52^{\circ} \mathrm{C}$ (Ogan-Kuqa river oasis) in autumn, and $-7.44^{\circ} \mathrm{C}$ (Hotan River oasis) to $-1.61^{\circ} \mathrm{C}$ (Aksu River oasis) in spring. The spatial distribution characteristics of OCIE intensity during daytime also indicated that OCIE intensities of the Kaxgar River, Yarkant River, Hotan River and Keriya River oases in the southern Tarim Basin were higher than those of the Bosten Lake, Konqi River, Ogan-Kuqa river and Aksu River oases in the northern Tarim Basin.

During the nights of spring, summer and autumn, only the Bosten Lake oasis showed cold island effect with the OCIE intensities of $-1.31{ }^{\circ} \mathrm{C},-0.71{ }^{\circ} \mathrm{C}$ and $-0.54{ }^{\circ} \mathrm{C}$, respectively. Other oases, such as Konqi River, Ogan-Kuqa river and Aksu River oases, only showed weak cold island effect, with the OCIE intensities during nighttime ranging from $-0.85^{\circ} \mathrm{C}$ to $-0.12^{\circ} \mathrm{C}$. The remaining oases did not show the OCIE, and the OCI during nighttime exhibited heat island effect. Moreover, such oasis heat island effect during nighttime was highest in autumn, followed by spring and summer. These results indicated that the oases undergo rhythmic changes in cold and heat island effects during day and night.

\subsection{Temporal and spatial variation of OCIE}

Areas of OCI changed with the seasons in all oases of Tarim Basin (Fig. 4a). The total OCI area occupied $62.34 \%, 59.53 \%$ and $56.99 \%$ of the total area of all oases in summer, autumn and spring, respectively. The areas of OCI with different OCIE intensities also showed seasonal variations. The area of OCI with strong OCIE was largest in summer, followed by autumn and spring. The percentages of areas of OCI with strong OCIE to the total oasis area were $31.47 \%, 12.64 \%$ and 

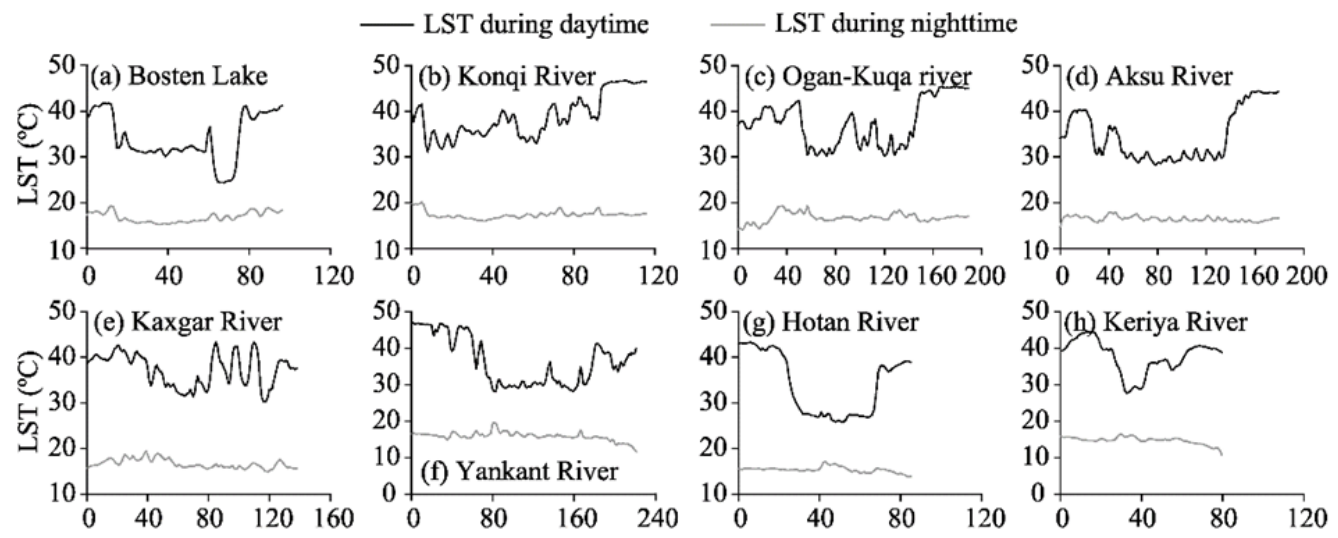

Distance from $\mathrm{N}$ to $\mathrm{S}(\mathrm{km})$ Distance from $\mathrm{N}$ to $\mathrm{S}(\mathrm{km})$

Distance from $\mathrm{N}$ to $\mathrm{S}(\mathrm{km})$ Distance from $\mathrm{N}$ to $\mathrm{S}(\mathrm{km})$
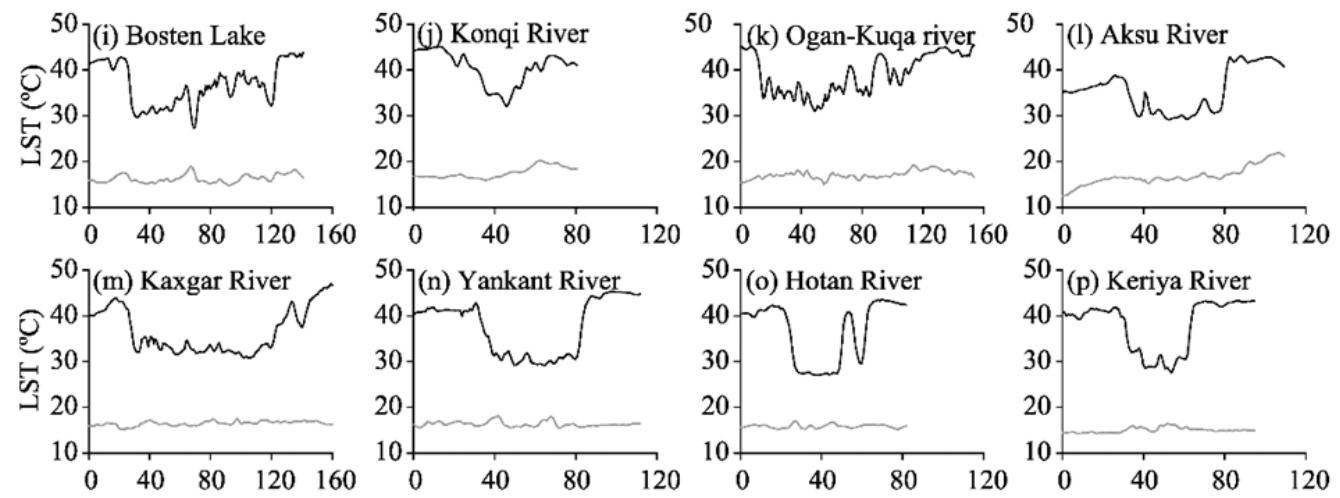

Distance from W to $\mathrm{E}(\mathrm{km})$ Distance from $\mathrm{W}$ to $\mathrm{E}(\mathrm{km})$ Distance from $\mathrm{W}$ to $\mathrm{E}(\mathrm{km})$ Distance from $\mathrm{W}$ to $\mathrm{E}(\mathrm{km})$

Fig. 2 Change trend of land surface temperature (LST) along the north-south (NS) and west-east (WE) directions (considering the city/town as the center) of the eight main oases in the Tarim Basin
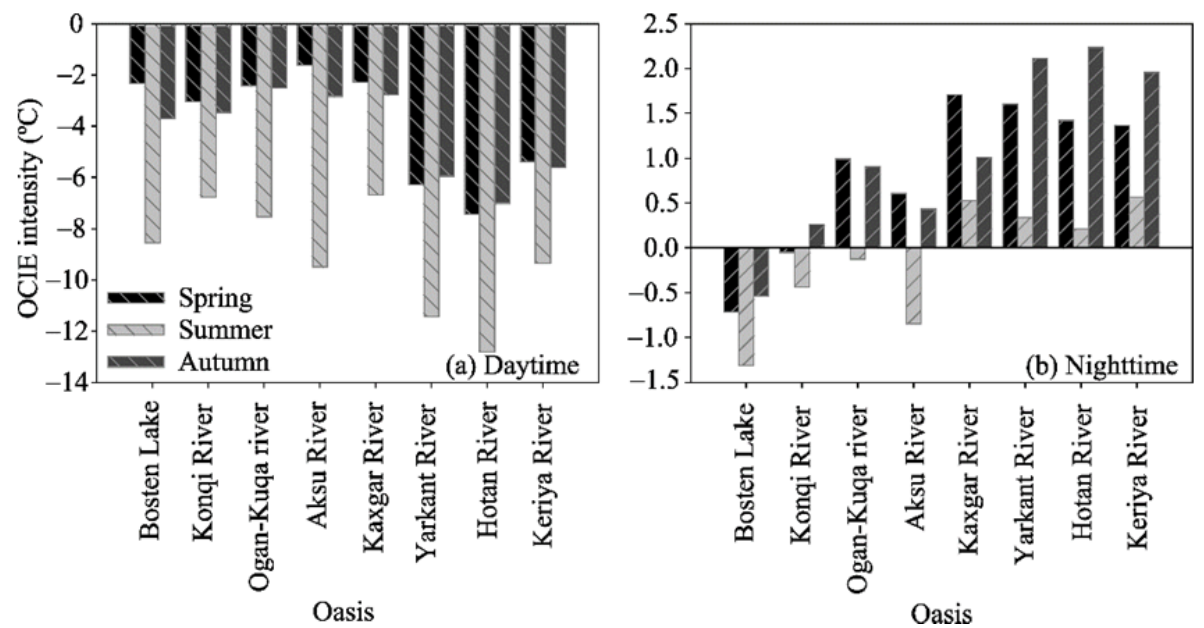

Fig. 3 Changes in OCIE (oasis cold island effect) intensity in spring, summer and autumn in different oases of Tarim Basin. (a) and (b) indicate OCIE intensity during daytime and nighttime, respectively.

$10.67 \%$ in summer, autumn and spring, respectively. The area of OCI with medium OCIE was largest in autumn and accounted for $18.42 \%$ of the total oasis area. Meanwhile, in spring and summer, the percentages of areas of OCI with medium OCIE to total oasis area were $15.90 \%$ and $12.02 \%$, respectively. The percentages of areas of OCI with weak OCIE to the total oasis area were $30.43 \%, 28.44 \%$ and $18.84 \%$ in spring, autumn and summer, respectively. The percentages of total OCI area of each oasis to the total oasis area decreased in the order of Bosten Lake, 
Ogan-Kuqa river, Yarkant River, Kaxgar River, Aksu River, Konqi River, Hotan River and Keriya River oases, with the values of $69.36 \%, 68.91 \%, 68.72 \%, 64.59 \%, 59.54 \%, 52.88 \%$, $50.21 \%$ and $42.74 \%$, respectively.

We constructed a comprehensive OCIE index to assess the cold island effect of each oasis (Fig. 4b). Results showed that the comprehensive OCIE index of all oases was highest in summer, followed by autumn and spring, similar to the changing trend in the area of OCI. For each oasis, the OCIE during the growing season decreased in the order of Bosten Lake, Yarkant River, Ogan-Kuqa river, Kaxgar River, Aksu River, Hotan River, Konqi River and Keriya River oases. The comprehensive OCIE indices of these oases were 1.42, 1.36, 1.28, 1.19, 1.07, 0.98, 0.94 and 0.67 , respectively. These results indicated that the larger the oasis scales, the stronger the OCIEs.

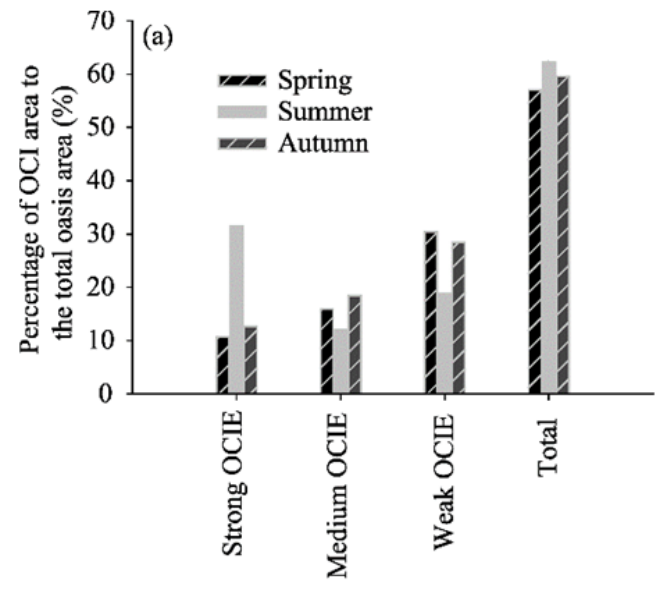

OCIE intensity

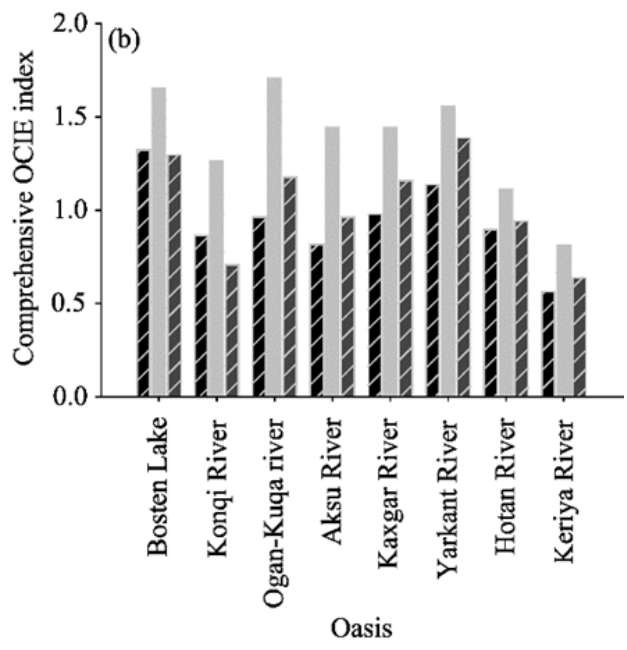

Fig. 4 The percentage of areas of OCI (oasis cold island) with different OCIE intensities relative to the total oasis area (a) and the comprehensive OCIE index of each oasis (b) in spring, summer and autumn from 2000 to 2013

\subsection{Factors influencing the OCIE}

The OCIE is a result of high evapotranspiration in an oasis. The farmland, water area and natural vegetation (forest and grassland distributed outside the farmland and water area) are the main contributors of high evapotranspiration. Correlation analyses between the metrics of main land use/cover types and the OCIE (Table 3) showed that farmland and water area are the two main contributors to the OCIE, and the influence of farmland is more significant. Natural vegetation was found to have almost no influence on the OCIE, except that the grassland had weak impact on the cold island effect. The landscape diversity index was not correlated with the OCIE, but the metrics of farmland and water area, such as the area and aggregation, significantly influenced the OCIE.

The area of OCI with weak OCIE was influenced by the mean patch area $(r=-0.84)$, patch cohesion $(r=-0.78)$, splitting index $(r=0.77)$ of farmland, mean shape index $(r=-0.76)$ of water area, and aggregation metric index $(r=0.72)$ of grassland. The larger mean patch area (core area) and the more centralized distribution area of farmland always led to smaller area of OCI with weak OCIE. By contrast, the wider separation of farmland paths and the more complex shape of water area indicated a larger area of OCI with weak OCIE. The areas of OCI with strong and medium OCIEs were mainly determined by the area and aggregation metrics of farmland, including the PLAND (percentage of landscape), LPI (largest patch index), AREA_MN (mean patch area), COHESION (patch cohesion index) and SPLIT (splitting index). The larger patch area and the higher dominance and aggregation of farmland generally led to larger area of OCI with strong OCIE. However, the patch area and dominance of water area were negatively correlated with the areas of OCI with strong and medium OCIEs, which indicated that the wider separation of water area paths usually lead to the larger areas of OCI with strong and medium OCIEs. The results also showed that the changing trend in area of OCI with weak OCIE was 
opposite of the changing trend in area of OCI with strong and medium OCIEs. In addition, when the area of OCI with weak OCIE was smaller, the areas of OCI with strong and medium OCIEs were larger. The total OCI area and comprehensive OCIE index were mainly controlled by the areas of OCI with strong and medium OCIEs. Therefore, their correlation with the aforementioned metrics of land use/cover types was consistent with the correlation between the area of OCI with strong OCIE and these metrics.

Table 3 Correlation of the metrics of main land use/cover types with the areas of OCI with different OCIEs and the comprehensive OCIE index

\begin{tabular}{|c|c|c|c|c|c|c|c|}
\hline $\begin{array}{l}\text { Land } \\
\text { use/cover } \\
\text { type }\end{array}$ & Metric & Index & $\begin{array}{c}\text { Area of } \\
\text { OCI with } \\
\text { weak OCIE }\end{array}$ & $\begin{array}{c}\text { Area of OCI } \\
\text { with medium } \\
\text { OCIE }\end{array}$ & $\begin{array}{c}\text { Area of OCI } \\
\text { with strong } \\
\text { OCIE }\end{array}$ & $\begin{array}{l}\text { Total OCI } \\
\text { area }\end{array}$ & $\begin{array}{l}\text { Comprehensive } \\
\text { OCIE index }\end{array}$ \\
\hline \multirow[t]{7}{*}{ Farmland } & Area and & PLAND & -0.47 & $0.81^{*}$ & 0.65 & $0.74^{*}$ & $0.75^{*}$ \\
\hline & \multirow[t]{2}{*}{ edge } & LPI & -0.48 & $0.70^{*}$ & 0.67 & $0.76^{*}$ & $0.74^{*}$ \\
\hline & & AREA_MN & $-0.84^{*}$ & 0.38 & $0.81^{*}$ & 0.67 & $0.77^{*}$ \\
\hline & Core area & CPLAND & -0.52 & $0.77^{*}$ & $0.73^{*}$ & $0.82^{*}$ & $0.81^{*}$ \\
\hline & \multirow[t]{3}{*}{ Aggregation } & ENN_MN & -0.32 & -0.16 & 0.33 & 0.19 & 0.26 \\
\hline & & COHESION & $-0.78^{*}$ & $0.73^{*}$ & $0.82^{*}$ & $0.77^{*}$ & $0.85^{*}$ \\
\hline & & SPLIT & $0.77^{*}$ & -0.70 & $-0.79^{*}$ & $-0.76^{*}$ & $-0.83^{*}$ \\
\hline Grassland & Aggregation & AI & $0.72^{*}$ & -0.43 & -0.52 & -0.41 & -0.49 \\
\hline \multirow{6}{*}{$\begin{array}{l}\text { Water } \\
\text { area }\end{array}$} & Area and & LPI & 0.57 & $-0.81^{*}$ & $-0.81^{*}$ & $-0.86^{* *}$ & $-0.88^{* *}$ \\
\hline & edge & AREA_MN & 0.66 & $-0.75^{*}$ & $-0.73^{*}$ & $-0.74^{*}$ & $-0.79^{*}$ \\
\hline & \multirow[t]{2}{*}{ Shape } & SHAPE_MN & $-0.76^{*}$ & 0.60 & 0.44 & 0.39 & 0.46 \\
\hline & & FRAC_MN & $-0.84^{*}$ & 0.61 & 0.53 & 0.46 & 0.54 \\
\hline & Core area & CORE_MN & 0.65 & $-0.76^{*}$ & -0.61 & -0.62 & -0.65 \\
\hline & Aggregation & SPLIT & -0.39 & 0.54 & $0.74^{*}$ & $0.77^{*}$ & $0.78^{*}$ \\
\hline
\end{tabular}

Note: ${ }^{*}$ and ${ }^{* *}$ mean significance at $P<0.05$ and $P<0.01$ levels, respectively. OCI, oasis cold island; OCIE, oasis cold island effect. This table only listed the main land use/cover types significantly correlated with the OCIE.

\subsection{Impacts of OCIE on air temperature}

The Tarim Basin has 43 meteorological stations in total. They are distributed across the oases, in addition to four located in the mountainous areas (Fig. 1). Thus, the data observed at these stations only reflect the meteorological elements of the oases. In the last 50 years, the oasis evolution process just was the process of artificial vegetation replacing the natural vegetation. Therefore, the impact of OCIE on observed meteorological elements, especially air temperature, is an important research field.

We primarily extracted the mean LST of the 1-km buffer zone with each station as the center. The regression relationship between the mean LST and observed air temperature in spring, summer and autumn from 2000 to 2013 was established (Fig. 5). The results showed that the mean LST was significantly correlated with the mean, maximum and minimum air temperatures. Furthermore, air temperature could be estimated well using the LST data series.

We also extracted the mean LST of the main land use/cover types in different seasons based on the land use/cover map. As shown in Table 4, the mean LST of the desert was the highest across all seasons, whereas the mean LSTs of the water area and farmland were lower.

This study provided the following two scenarios to analyze the impacts of OCIE on air temperature: (1) the farmland in oasis is replaced by forest, and (2) the farmland in oasis is replaced by grassland. We also extracted the mean LST of the $1-\mathrm{km}$ buffer zone with each station as the center under the two scenarios. We then estimated the mean, maximum and minimum air temperatures under the two scenarios using the regression relationship of LST and observed air temperature (Fig. 6). The simulation results showed that the mean, maximum and minimum air temperatures will increase significantly if the farmland is replaced by forest or grassland. Such a heating effect will be most evident in summer, followed by spring and autumn. Furthermore, the 
heating effect of the farmland being replaced by grassland will be greater than that of the farmland being replaced by forest. If the farmland is replaced by forest and grassland, the mean air temperature in summer will increase by $1.66^{\circ} \mathrm{C}$ and $2.08^{\circ} \mathrm{C}$, respectively; and the maximum
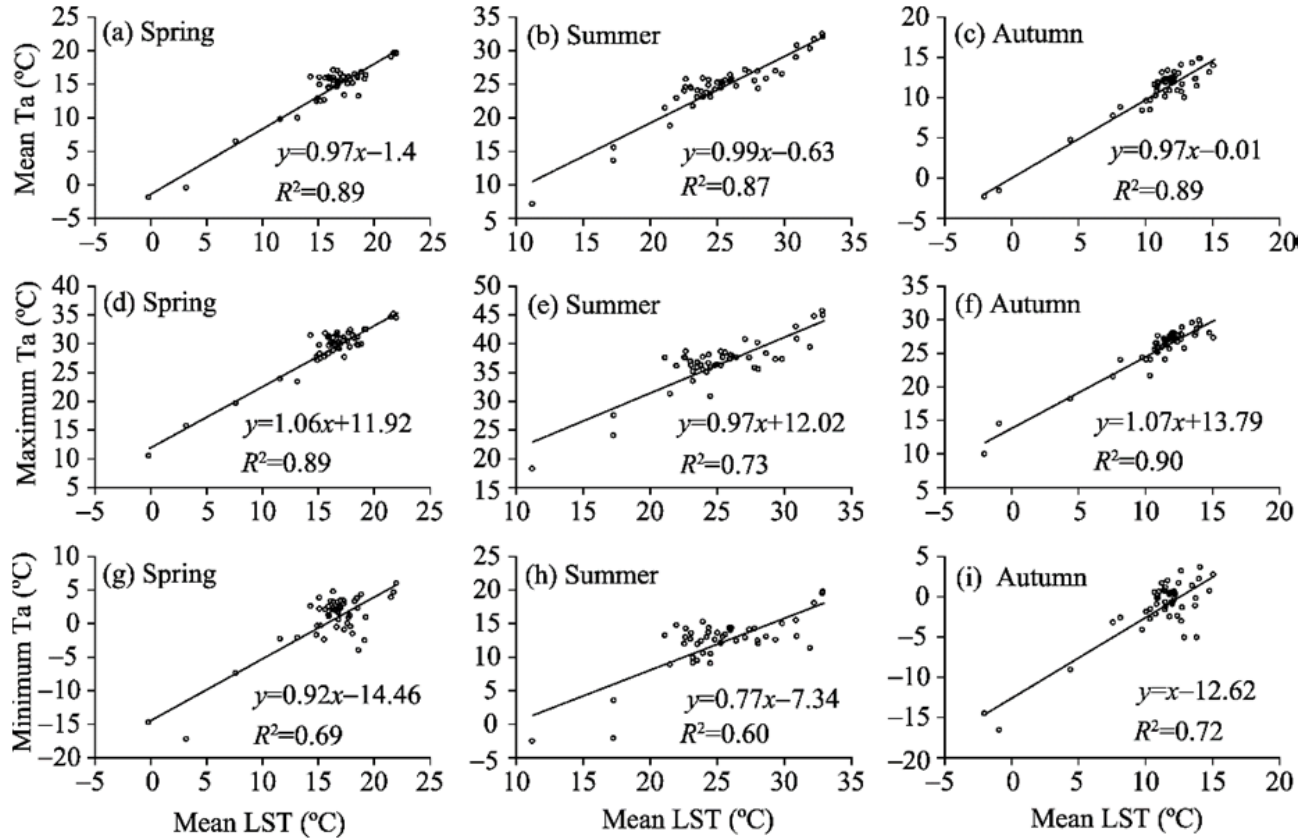

Fig. 5 Scatter plots between mean LST (mean value of LST during daytime and nighttime) and mean, maximum and minimum observed air temperatures of 43 meteorological stations in the Tarim Basin. Ta, air temperature.
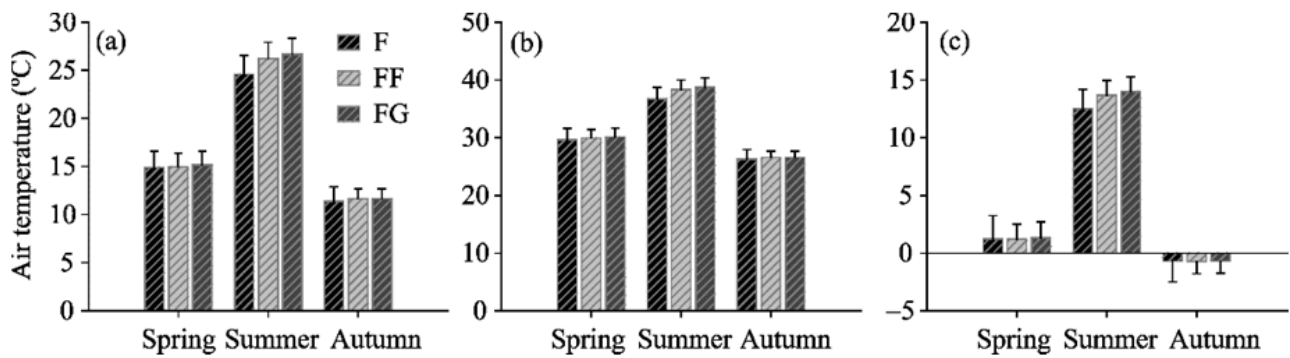

Fig. 6 Estimated seasonal (a) mean, (b) maximum and (c) minimum air temperatures under two scenarios (farmland being replaced by (1) forest and (2) grassland) based on the regression relationship of LST and observed air temperature. Observed air temperature data were collected from 43 stations in the Tarim Basin. F, farmland; FF, farmland is replaced by forest; FG, farmland is replaced by grassland.

Table 4 Mean seasonal LST (land surface temperature) of different land use/cover types in spring, summer and autumn

\begin{tabular}{lccc}
\hline \multirow{2}{*}{ Land use/cover type } & LST in spring & LST in summer & LST in autumn \\
\cline { 2 - 4 } & & $\left.{ }^{\circ} \mathrm{C}\right)$ & 12.02 \\
Water area & 14.50 & 25.12 & 11.28 \\
Farmland & 16.72 & 24.90 & 12.02 \\
Forest & 17.43 & 28.29 & 12.18 \\
Grassland & 17.67 & 28.91 & 11.42 \\
Town & 16.73 & 24.94 & 12.04 \\
Gobi and saline alkali land & 17.40 & 29.35 & 12.89 \\
Desert & 18.78 & 30.72 & \\
\hline
\end{tabular}


air temperature will increase by $1.64^{\circ} \mathrm{C}$ and $2.05^{\circ} \mathrm{C}$, respectively. Meanwhile, the minimum air temperature in summer will increase by $1.14^{\circ} \mathrm{C}$ and $1.47^{\circ} \mathrm{C}$, respectively. Under the same scenarios, the mean air temperature in spring will increase by $0.01^{\circ} \mathrm{C}$ and $0.21^{\circ} \mathrm{C}$, respectively; and the maximum air temperature will increase by $0.30^{\circ} \mathrm{C}$ and $0.47^{\circ} \mathrm{C}$, respectively. Such a heating effect will be weak in autumn, and the mean air temperature will only increase by $0.23^{\circ} \mathrm{C}$ and $0.26^{\circ} \mathrm{C}$, respectively; while the maximum air temperature will only increase by $0.29^{\circ} \mathrm{C}$ and $0.31^{\circ} \mathrm{C}$, respectively. The results also indicated that the minimum air temperature will decrease in spring and autumn, but will significantly increase in summer. If the farmland is replaced by forest, the minimum air temperature will decrease by $0.05^{\circ} \mathrm{C}$ and $0.04^{\circ} \mathrm{C}$ in spring and autumn, respectively. However, if the farmland is replaced by grassland, the minimum air temperature will increase by $0.10^{\circ} \mathrm{C}$ in spring, but decrease by $0.04^{\circ} \mathrm{C}$ in autumn.

\section{Discussion}

\subsection{Characteristics of OCIE}

In this study, we found that oasis had significant cold island effect compared to the desert surrounding the oasis. Moreover, the OCIE intensity was highest in summer, followed by autumn and spring because of evapotranspiration from the oasis surface, which cools the oasis (Chu et al., 2005; Qiu et al., 2013). Evapotranspiration was highest in summer compared to autumn and spring. Based on the results of OCIE intensity and regression relationship between LST and observed air temperature, we concluded that air temperatures of the oasis were $3^{\circ} \mathrm{C}$ to $7^{\circ} \mathrm{C}$ lower than those of the desert, which was consistent with previous reports (Taha et al., 1991; Potchter et al., 2008). Previous studies also reported that the OCIE exhibits diurnal variation (Taha et al., 1991; Wen et al., 2005). In this study, we found that the oasis exhibited OCIE during daytime, while it might show a heat island effect during nighttime.

Furthermore, the OCIE had evident spatial variation. The cold island effects of Hotan River, Yarkant River and Keriya River oases located in the southern edge of Tarim Basin were higher than those of Bosten Lake, Konqi River and Ogan-Kuqa river oases distributed in the northern edge of the basin. This difference may be attributed to the main stream of Tarim River located in the northern edge of the basin, and in the river section more water areas and desert-oasis ecotones were formed in the peripheries of the oases in this region. These likely resulted in the difference of LST between the oasis and peripheral desert zone.

Throughout the entire growing season, the Bosten Lake oasis had the highest OCIE intensity, and the Hotan River oasis had the largest total OCI area. The variations of OCIE intensity and total OCI area in the study area were not consistent. This result indicated that the spatial variation of OCIE could not be obtained if our analysis only focused on OCIE intensity or OCI area. To address this issue, we constructed a comprehensive OCIE index that considers both the OCIE intensity and area of OCI. The results showed that the OCIE across different oases decreased in the order of Bosten Lake, Yarkant River, Ogan-Kuqa river, Kaxgar River, Aksu River, Hotan River, Konqi River and Keriya River oases. This order showed that the oasis scale and water area generally determined the OCIE. Previous studies have shown that the driving forces of OCIE were the mesoscale and secondary circulations (Chu et al., 2005; Liu et al., 2007; Li et al., 2011). Therefore, larger oasis or water area may indicate a better mesoscale or secondary circulation, which always lead to a sizeable cold island effect.

\subsection{Factors influencing the OCIE}

Local winds, particularly wind speed ( $\mathrm{Su}$ and $\mathrm{Hu}, 1987$ ), vegetation cover and land surface conditions of an oasis (Wan and Li, 1997; Schwarz et al., 2011) are the main factors influencing the OCIE. Therefore, the spatial distribution characteristics of the main land use/cover types, including farmland, water area, forest and grassland, could directly influence the OCIE. Our results indicated that farmland and water area are the two most important contributing factors for the OCIE. By contrast, forest and grassland had almost no significant influence on the OCIE. These results can be attributed to the sharp reduction in the area of the desert-oasis ecotone and the degraded natural vegetation due to human activities (Yang et al., 2006).

Table 3 showed that the area and aggregation degree (mainly including COHESION and SPLIT) 
of farmland patch are positively correlated with the OCIE. However, these two metrics of water area patches were negatively correlated with the OCIE. This phenomenon may be caused by the influence of water area on the OCIE mainly through direct water surface evaporation and evapotranspiration from wetlands. In certain water areas, if the patch areas are smaller and the patches are more split, the effective influence range will be larger and conducive to forming more wetlands, which will increase evapotranspiration and promote the OCIE.

\subsection{Impact of OCIE on air temperature}

With the increase of population and expansion of cultivated lands in recent years (Zhang et al., 2003; Jiang et al., 2005), artificial oases have rapidly expanded and artificial vegetation have replaced natural vegetation (Fan et al., 2002; Yang et al., 2006). At present, 39 meteorological stations in the Tarim Basin are located in the oasis regions (plain region), and 4 stations in the mountainous regions. Thus, the air temperatures observed at these stations should be significantly affected by the evolution process of oasis. Results of simulations indicated that if the farmland is replaced by forest and grassland, the mean air temperature will increase by $1.66^{\circ} \mathrm{C}$ and $2.08^{\circ} \mathrm{C}$ in summer, respectively, and increase by about $0.2^{\circ} \mathrm{C}$ in spring and autumn. This result indicated that the expansion of artificial oasis could enhance the OCIE, which could significantly lower the air temperature, especially in summer. Air temperature in arid region of Northwest China was in a heated state from 1981 to 2010 , and the contribution of the seasonal changes to annual temperature increases were $19.3 \%, 13.7 \%, 23.6 \%$ and $43.4 \%$ in spring, summer, autumn and winter, respectively ( $\mathrm{Li}$ et al., 2012). This phenomenon only strengthened the influence of OCIE on air temperature. Temperature variation in summer only weakly influenced the annual temperature variation because the OCIE was highest in summer. Based on this view, if the farmland in oasis is completely replaced by natural vegetation, the heating rate is predicted to be higher in the entire arid region of Northwest China. In winter, growth of crops and natural vegetation ceased, and evapotranspiration significantly decreased, and, consequently, the OCIE was absent. Therefore, temperature increase in winter had the maximum impact on annual temperature variation and was possibly one of the reasons for the significant increase in winter temperature in arid region.

In this study, we also calculated the seasonal mean air temperature in the Tarim Basin (according to a grid of $1 \mathrm{~km} \times 1 \mathrm{~km}$ ) based on the MODIS LST data and the regression relationship between the mean LST and observed air temperature (Fig. 5). Results showed that the mean air temperatures were $16.43^{\circ} \mathrm{C}, 29.20^{\circ} \mathrm{C}$ and $12.18^{\circ} \mathrm{C}$ in spring, summer and autumn, respectively. Statistical adjustments of the observed data yielded mean air temperatures of $14.31^{\circ} \mathrm{C}, 24.30^{\circ} \mathrm{C}$ and $10.87^{\circ} \mathrm{C}$ for spring, summer and autumn, respectively. The calculated mean air temperatures were evidently higher than the statistical mean air temperatures, e.g. the former was $4.9^{\circ} \mathrm{C}$ higher than the latter in summer in the entire basin. This result may be attributed to the following causes: (1) the large difference in local circulation, energy and water balance between the desert and oasis landscapes (Wen et al., 2005; Feng et al., 2006; Ji et al., 2011); (2) the area of deserts is far larger than that of the oases, which is generally less than $10 \%$ of the total basin area; and (3) almost all meteorological stations are located in the oases. These results indicated that the meteorological stations located in the oases are lack of general representative and the observed data cannot accurately reflect the overall meteorological characteristics in the Tarim Basin, such as temperature and relative humidity.

\section{Conclusions}

Cold island effects were found to be common in the oases of Tarim Basin. The average difference between the minimum LST of oasis and the mean LST of desert was $12.95^{\circ} \mathrm{C}$ in the entire basin. The OCIE intensity during daytime was highest in summer with an average OCIE intensity of $-9.08^{\circ} \mathrm{C}$, followed by autumn, with the value of $-4.24^{\circ} \mathrm{C}$. The area of OCI showed seasonal changes, and was typically largest in summer. Similar to the change trend in the area of OCI, the comprehensive OCIE index of all oases was also highest in summer, followed by autumn and spring. Across all oases, the OCIE during the growing season followed this order from the strongest to the weakest: Bosten Lake, Yarkant River, Ogan-Kuqa river, Kaxgar River, Aksu River, Hotan River, Konqi River and Keriya River oases. 
The OCIE is a result of high evapotranspiration in the oases. Farmland and water area were found to be the main contributors for OCIE, with the influence of farmland being more significant compared to water area. Simulations based on LST and observed air temperature data showed that the mean, maximum and minimum air temperatures will increase significantly if the farmland is replaced by forest or grassland. Such a heating effect will be most evident in summer, followed by spring and autumn. Furthermore, the heating effect of farmland being replaced by grassland will be greater than that of farmland being replaced by forest.

\section{Acknowledgements}

This work was funded by the National Natural Science Foundation of China (41571109).

\section{References}

Chen Y N, Chen Z S. 2013. Analysis of oasis evolution and suitable development scale for arid regions: a case study of the Tarim River Basin. Chinese Journal of Eco-Agriculture, 21(1): 134-140. (in Chinese)

Chu P C, Lu S H, Chen Y C. 2005. A numerical modeling study on desert oasis self-supporting mechanisms. Journal of Hydrology, 312(1-4): 256-276.

Fan Z L, Xia X C, Shen Y L, et al. 2002. Utilization of water resources, ecological balance and land desertification in the Tarim Basin, Xinjiang. Science in China Series D: Earth Sciences, 45(S1): 102-108.

Feng Q, Si J H, Zhang Y W, et al. 2006. Microclimatic characteristics of the Heihe oasis in the hyperarid zone of China. Journal of Geographical Sciences, 16(1): 34-44.

Han B, Lü S H, Ao Y H. 2010. Analysis on the interaction between turbulence and secondary circulation of the surface layer at Jinta Oasis in summer. Advances in Atmospheric Sciences, 27(3): 605-620.

Ji X B, Zhao W Z, Kang E S, et al. 2011. Carbon dioxide, water vapor, and heat fluxes over agricultural crop field in an arid oasis of Northwest China, as determined by eddy covariance. Environmental Earth Sciences, 64(3): 619-629.

Jiang L W, Tong Y F, Zhao Z J, et al. 2005. Water resources, land exploration and population dynamics in arid areas-the case of the Tarim River basin in Xinjiang of China. Population and Environment, 26(6): 471-503.

Li B F, Chen Y N, Shi X. 2012. Why does the temperature rise faster in the arid region of northwest China? Journal of Geophysical Research: Atmospheres (1984-2012), 117(D16): 16115, doi: 10.1029/2012JD017953.

Li W L, Lü S H, Fu S M, et al. 2011. Numerical simulation of fluxes generated by inhomogeneities of the underlying surface over the Jinta Oasis in Northwestern China. Advances in Atmospheric Sciences, 28(4): 887-906.

Liu B, Zhao W Z, Chang X X, et al. 2010. Water requirements and stability of oasis ecosystem in arid region, China. Environmental Earth Sciences, 59(6): 1235-1244.

Liu S H, Liu H P, Hu Y, et al. 2007. Numerical simulations of land surface physical processes and land-atmosphere interactions over oasis-desert/Gobi region. Science in China Series D: Earth Sciences, 50(2): 290-295.

Potchter O, Goldman D, Kadish D, et al. 2008. The oasis effect in an extremely hot and arid climate: the case of southern Israel. Journal of Arid Environments, 72(9): 1721-1733.

Qiu G Y, Li H Y, Zhang Q T, et al. 2013. Effects of evapotranspiration on mitigation of urban temperature by vegetation and urban agriculture. Journal of Integrative Agricluture, 12(8): 1307-1315.

Schwarz N, Lautenbach S, Seppelt R. 2011. Exploring indicators for quantifying surface urban heat islands of European cities with MODIS land surface temperatures. Remote Sensing of Environment, 115(12): 3175-3186.

Su C X, Hu Y Q. 1987. The structure of the oasis cold island in the planetary boundary layer. Acta Meteorologica Sinica, 45(3): 322-328. (in Chinese)

Taha H, Akbari H, Rosenfeld A. 1991. Heat island and oasis effects of vegetative canopies: micro-meteorological field-measurements. Theoretical and Applied Climatology, 44(2): 123-138.

Wan Z M, Li Z L. 1997. A physics-based algorithm for retrieving land-surface emissivity and temperature from EOS/MODIS data. IEEE Transactions on Geoscience and Remote Sensing, 35(4): 980-996.

Wen L J, Lü S H, Chen S Q, et al. 2005. Numerical simulation of cold island effect in Jinta Oasis summer. Plateau Meteorology, 24(6): 865-871. (in Chinese)

Yang F X, Mu G J, Yue J, et al. 2006. Formation causes and evolution of oases in arid areas. Arid Land Geography, 29(1): 7075. (in Chinese)

Yang Y B, Su W Z, Jiang N. 2006. Time-space character analysis of urban heat island effect in Nanjing city using remote sensing. Remote Sensing Technology and Application, 21(6): 488-492. (in Chinese)

Zhang H, Wu J W, Zheng Q H, et al. 2003. A preliminary study of oasis evolution in the Tarim Basin, Xinjiang, China. Journal of Arid Environments, 55(3): 545-553. 